\title{
Research Article \\ Estimation of Crash Severity on Mountainous Freeways in Chongqing
}

\author{
Yunwei Meng ${ }^{1,2}$ \\ ${ }^{1}$ The Key Laboratory of Road and Traffic Engineering, Ministry of Education, Tongji University, Shanghai 201804, China \\ ${ }^{2}$ China Merchants Chongqing Communications Technology Research \& Design Institute Co., Ltd., Chongqing 400067, China \\ Correspondence should be addressed to Yunwei Meng; 13mengyunwei@tongji.edu.cn
}

Received 2 November 2016; Accepted 31 January 2017; Published 19 February 2017

Academic Editor: Xiangyu Meng

Copyright (c) 2017 Yunwei Meng. This is an open access article distributed under the Creative Commons Attribution License, which permits unrestricted use, distribution, and reproduction in any medium, provided the original work is properly cited.

\begin{abstract}
Mountainous freeways always suffer from accidents due to special terrain, weather conditions, driving environment, and so on. Based on the records of 898 accidents that occurred on mountainous freeways in Chongqing during the past 6 years, the partial proportional odds model is used to identify the factors affecting the accident severity. The time of the accident, season, involvement of trucks, accident characteristics, speeding, maximum driving experience of involved drivers, and weather and road conditions are found to be important for the levels of accident severity. Zero to 6 a.m. and 19 to 24 p.m. are the times prone to serious traffic accidents. The probability of serious traffic accidents in summer and autumn is greater than that in spring and winter. Once a truck is involved in an accident, the consequence is often more severe. Turnover and speeding will result in a grave accident. When there is an experienced driver, the probability of serious traffic accidents is low. The fog is extremely unfavorable weather conditions. The probability of serious accident happening in the downgrade, ramp, curve, bridge, and tunnel sections is greater than the others. The results aim to provide valuable reference for traffic safety on mountainous freeways.
\end{abstract}

\section{Introduction}

In China, mountainous freeways are subjected to high frequency of traffic accidents and have larger probability of a serious crash. This is partly due to the road alignment which has a small curve radius and large longitudinal slope. The external environment is another influencing factor, including changeable climatic conditions, high proportion of bridge, and tunnels. In China, one-third of national land area is covered by mountains. Most of the mountainous freeways are two-way four-lane roads. As the rapid development of mountainous freeways and increasing traffic volume, the range of freeways subjected to traffic accidents is increasing. Chongqing is located in the southwest of China and has a typical mountainous terrain. It is cold in winter and extremely hot in summer. The serious consequence caused by traffic accidents has attracted more and more attention from traffic management departments. It is necessary to gain an insight into the influencing factors such as vehicle, driving mistake, unreasonable road design. Once the accident happened, the traffic management staff often use two kinds of ways to record the traffic accident severity, namely, the property damage and the personnel casualty method. According to the property damage, the accident severity can be classified into vehicle damage only accident, road property damage only accident, and vehicle-road property damage accident. According to the number of casualties and injuries, the severity of accidents can be classified into minor injury accident, serious injury accident, and fatal accident. In the record report, there is no detailed research on the crash severity. In order to mitigate the hazards of serious accidents, it is necessary to study the effect of drivers, vehicles, roads, and weather on the severity of traffic accidents.

Among the various factors influencing the crash severity, too young or too old and female bus drivers will aggravate the severity of accidents [1]. Zhang et al. [2] also found that the younger and older drivers and female drivers contribute to severe mountainous freeway crashes. The one-vehicle and two-vehicle collision accidents have different severities [3]. This means that the crash severity is dependent on the number of vehicles involved in the collision and the form of accidents. It was found that drivers' distraction, alcohol 
use, and being emotional led to higher severity of largetruck crashes [4]. Roque et al. [5] studied the effect of various slope ratio on the fatal severity of vehicle turnover. To reduce the ran-off-road crash severities, it is necessary to design freeways according to the concept of forgiving roadside, which provide fault tolerant capabilities. Roadside objects also have important effect on the severity of accidents [6]. Some researchers emphasized the value of the surface condition of road. Previous studies showed that there was obvious relation between the road surface condition and accident severity. The decrease of the antislide coefficient or surface and the decrease of sight distance have an influence on the crash severity [7]. Abay et al. [8] found that the injury severity was related with the speed limit, presence or absence of center dividers, and involvement of head-on collision. Meanwhile, Polus et al. believed that crash rate and severity could be predicted by the highway's infrastructure features [9]. Weather conditions such as rain, snow, and temperature have important effect on the occurrence and severity of mountainous freeway accidents [10]. However, these studies focus on limited influencing factors. More factors should be considered to comprehensively study the level of severity of accidents which depends on multiple factors.

Many research methods have been used in previous studies on the crash severity. The binary or multivariate logit models were widely used since the accident severity could be considered as a discrete variable $[3,5]$. The ordered classification model was used to study the severity caused by various types of vehicles and collisions [4]. The ordered logit and probit models have also been used to study the influencing factors on the crash severity. A generalized ordered logistic regression model was applied to identify the factors affecting the crash severity on hard shoulder and the main carriageway [11]. For considering heteroscedasticity in the effects of explanatory variables on injury severity, the heteroscedastic ordered logit model was used [3]. The heteroskedastic ordered probit model was also applied to study the impact of vehicle, occupant, driver, and environmental characteristics on injury outcomes for those involved in crashes with heavy-duty trucks [12]. A generalized ordered logistic regression model was applied to identify the factors affecting the accident severity such as vehicle characteristics, traffic, and environmental conditions [11]. Khan et al. studied the severity of accidents caused by vehicles passing over the medium divider and entering the opposite lane. The classification trees model and ordinal discrete choice model were compared to show their advantages and disadvantages [13]. A panel heteroskedastic ordered probit model was provided to simultaneously analyze the injury severities of all persons involved in a crash [4]. However, for either the ordered logit model or the probit model, invariant parameter estimates were assumed for the classification of accident severities. This assumption is not always valid as it includes significant artificial effects, that is, proportional odds assumption or parallel regression assumption [14]. An effective method should be found, which can test the assumption. If the collected data is no violation of the assumption, it could be executed in accordance with the original program. Otherwise the appropriate adjustment should be carried out during analysis process.
Some researchers applied the partial proportional odds model. A partial proportional odds model was proposed to relax the parallel-lines assumption constraint [15]. The results showed that the partial proportional odds model had adequate fit and performed well in terms of covariate significance and holdout prediction accuracy. Combined with the ability to accurately represent the theoretical process of crash severity prediction, it was believed that the partial proportional odds model is a favorable approach for analyzing crash severity [16].

The main objective of this paper is to investigate the influence of drivers' behavior, vehicle characteristics, and road and environmental conditions (and their combination) on the severity of traffic accidents on mountainous freeways in Chongqing, China. The partial proportional odds model was used to analyze the data recorded from 898 accidents occurring on a given mountainous freeway in Chongqing during the year of 2010 to 2015 . The source and classification of these accidents were studied. The main factors compounding the crash severity were identified.

\section{Date Collection}

In order to study the influence of driving behavior, vehicle characteristics, road conditions, time, locations, and accident form on the crash severity, a total of 898 accidents, occurring on a given mountainous freeway in Chongqing during 2010-2015, were collected and analyzed from administrative department.

The highway is of $62 \mathrm{~km}$ in length, $24.5 \mathrm{~m}$ in width, twin four-lane. Medium divider is used to separate the travelling vehicles in opposite direction. The design speed is $80 \mathrm{~km} / \mathrm{h}$ while limit speed is $120 \mathrm{~km} / \mathrm{h}$. The accumulated ratio in length of curve, upgrade and downgrade section, bridge, and tunnel is greater than $40 \%$. The highway is taken as typical expressway in mountainous area.

The crash severities were classified as follows: (1) minor accident: there is only loss or damage of properties but no injuries or casualties in accident; (2) moderate accident: there are slight injuries together with damage of road facilities and vehicles in accident; (3) serious accident: there is death or more than three severe injuries in the accident. According to this classification, the minor accidents (669 accidents) account for $74.5 \%$ of the total accidents, the moderate accidents (134 accidents), 14.9\%, and serious accidents, 10.6\% (95 accidents). Methods of statistical investigation were adopted to collect original records of traffic crashes from traffic police occurred on this mountainous freeway from 2010 to 2015 . The data were then processed by digital information processing technology.

The factors affecting the crash severity were summarized and classified according to the records from the scene of the accident. Detailed definition of the explanatory variables and frequency are shown in Table 1, where the frequency and percentage are based on the total of 898 accidents. It should be noted that dummy variables were used to represent the categorical variables. One possible way of coding the dummy variables is to give $k$ design values for $k$ levels of the categorical variables. 
TABLE 1: Variable description.

\begin{tabular}{|c|c|c|c|}
\hline Variable & Code & Frequency & Percentage (\%) \\
\hline \multirow{4}{*}{ Time } & $1=00: 00 \sim 06: 00$ & 137 & 15.3 \\
\hline & $2=06: 00 \sim 12: 00$ & 261 & 29.1 \\
\hline & $3=12: 00 \sim 18: 00$ & 324 & 36.1 \\
\hline & $4=18: 00 \sim 24: 00$ & 176 & 19.5 \\
\hline \multirow{2}{*}{ Number of involved vehicles } & $1=$ one vehicle & 537 & 59.8 \\
\hline & $2=2$ or more vehicles & 361 & 40.2 \\
\hline \multirow{4}{*}{ Season } & $1=$ spring $($ March-April $)$ & 133 & 14.8 \\
\hline & $2=$ summer (May-Oct. $)$ & 420 & 46.8 \\
\hline & $3=$ autumn (Nov.) & 50 & 5.6 \\
\hline & $4=$ winter $($ Dec. - Feb. $)$ & 295 & 32.8 \\
\hline \multirow{2}{*}{ Damage of properties } & $1=$ damage of vehicle or road alone & 590 & 65.7 \\
\hline & $2=$ damage of vehicle and road & 308 & 34.3 \\
\hline \multirow{2}{*}{ Involvement of trucks } & $0=$ no truck & 600 & 66.8 \\
\hline & $1=$ truck involved & 298 & 33.2 \\
\hline \multirow{2}{*}{ Public traffic vehicles } & $1=$ yes & 329 & 36.6 \\
\hline & $2=$ no & 569 & 63.4 \\
\hline \multirow{4}{*}{ Accident form } & $1=$ with fixed object & 469 & 52.2 \\
\hline & $2=$ sideswipe & 137 & 15.3 \\
\hline & $3=$ turnover & 61 & 6.8 \\
\hline & $4=$ rear-end & 231 & 25.7 \\
\hline \multirow{2}{*}{ Violation of speed limit } & $0=$ within speed limit & 817 & 91.0 \\
\hline & $1=$ beyond speed limit & 81 & 9.0 \\
\hline \multirow{3}{*}{ Maximum driving experience of at-fault driver } & $1=\leq 1$ year & 80 & 8.9 \\
\hline & $2=1-3$ years & 110 & 12.3 \\
\hline & $3=\geq 3$ years & 708 & 78.8 \\
\hline \multirow{5}{*}{ Weather } & $1=$ cloudy & 57 & 6.4 \\
\hline & $2=$ sunny & 568 & 63.3 \\
\hline & $3=$ rainy & 248 & 27.6 \\
\hline & $4=$ snow & 18 & 2.0 \\
\hline & $5=$ foggy & 7 & 0.7 \\
\hline \multirow{10}{*}{ Section form } & $1=$ straight & 437 & 48.7 \\
\hline & $2=$ toll station & 57 & 6.4 \\
\hline & $3=$ service area & 53 & 5.9 \\
\hline & $4=$ upgrade & 10 & 1.1 \\
\hline & $5=$ downgrade & 24 & 2.7 \\
\hline & $6=\operatorname{ramp}$ & 4 & 0.5 \\
\hline & $7=$ curve & 44 & 4.9 \\
\hline & $8=$ construction area & 57 & 6.4 \\
\hline & $9=$ bridge & 82 & 9.1 \\
\hline & $10=$ tunnel & 130 & 14.3 \\
\hline
\end{tabular}

\section{Methods}

The crash severity of mountainous freeway in Chongqing was classified into 3 levels, that is, minor, moderate, and serious accidents. Crash severity could be regarded as a discrete variable, and the generalized ordered logit model was used to represent the probability of each level. The logit model can be expressed as

$$
\begin{aligned}
& P\left(Y_{i}>j\right)=g\left(X \beta_{j}\right)=\frac{\exp \left(\alpha_{j}+X_{i} \beta_{j}\right)}{1+\left\{\exp \left(\alpha_{j}+X_{i} \beta_{j}\right)\right\}}, \\
& j=1,2, \ldots, M-1,
\end{aligned}
$$

where $X_{i}$ is a $p$-dimensional vector, representing values of $p$ explanatory variables in the $i$ th accident data, and $\beta_{i}$ is also 
a $p$-dimensional vector, representing the regression coefficient. $\alpha_{j}$ is the $j$ th cumulative logit intercept. $M$ is the number of types for ordered dependent variables. The probability of dependent variables in each level can be expressed as

$$
\begin{aligned}
P\left(Y_{i}=1\right) & =1-g\left(X_{i} \beta_{1}\right) \\
P\left(Y_{i}=j\right) & =g\left(X_{i} \beta_{j-1}\right)-g\left(X_{i} \beta_{j}\right) \\
\qquad & j=1,2, \ldots, M-1 \\
P\left(Y_{i}=M\right) & =g\left(X_{i} \beta_{M-1}\right) .
\end{aligned}
$$

The generalized ordered logit model may be subjected to parallel regression assumption, which means all of the explanatory variables have the same regression coefficient $\beta_{i}$. So a partial proportional odds model was proposed, which was advanced in [15].

$$
\begin{aligned}
P\left(Y_{i}>j\right) & =g\left(X_{i} \beta_{j}\right) \\
& =\frac{\exp \left(\alpha_{j}+X_{1 i}^{\prime} \beta_{j}+X_{2 i}^{\prime} \gamma_{j}\right)}{1+\exp \left(\alpha_{j}+X_{1 i}^{\prime} \beta_{j}+X_{2 i}^{\prime} \gamma_{j}\right)}, \quad j=1,2,
\end{aligned}
$$

where $X_{2 i}$ is a $q$-dimensional vector $(q \leq p)$, representing the values of $p$ explanatory variables varying with $j$ in the $i$ th crash severity. $\gamma_{j}$ is also a $q$-dimensional vector, representing regression coefficients related to the $q$ covariates in $X_{2 i}$.

In (3), each explanatory variable has one $\beta$ coefficient and $(k-2) \gamma$ coefficients where $k$ is the number of dependent variables $(k=3$ in this case). In addition, there are $(k-$ 1) $\alpha$ coefficients. The parameter $\gamma$ represents the degree of deviation ratio. The $\gamma$-parameterized partial proportional odds model inherits all the characteristics of the generalized ordered logit model and allows for different $\beta$ coefficients to each explanatory variable. This model is intended to examine parallel regression assumption. For a particular case of $\gamma_{j}=$ 0 , it does not violate the parallel line assumption, so (3) is reduced to the generalized logit model. If $\gamma_{j} \neq 0$, it violates the assumption and elastic analysis could be conducted to further analysis.

The cumulative distribution function can be obtained as (Williams, 2006)

$$
P\left(Y_{i} \leq j\right)=1-P\left(Y_{i}>j\right)=1-g\left(X \beta_{j}\right)=F\left(X \beta_{j}\right) .
$$

In this study, $M=3$, that is, 3 levels of crash severity. One $=$ minor accident, $2=$ moderate accident, and $3=$ serious accident. It can calculate the cumulative probability distribution of severity level as shown in

$$
\begin{aligned}
& P\left(Y_{i}=1\right)=F\left(X \beta_{1}\right) \\
& P\left(Y_{i}=2\right)=F\left(X \beta_{2}\right)-F\left(X \beta_{1}\right) \\
& P\left(Y_{i}=3\right)=1-F\left(X \beta_{2}\right) .
\end{aligned}
$$

\section{Results}

There is information related to the crash severity in the collected data of traffic accidents. The partial proportional odds model was used to analyze the effect of explanatory variables (as listed in Table 1) on the severity of accidents. The coefficients were determined by the maximum likelihood estimate method. The gologit2 program in the software STATA was used for the parameter estimation. The significance of explanatory variables was within the $95 \%$ confidence interval. The analysis result is shown in Table 2. It is found that eight explanatory variables, including time, season, trucks involved, accident form, speeding, maximum driving experience of at-fault driver, weather, and section form, show significant impact on crash severity on mountainous freeways. The $p$ values are less than 0.01 , so they are not listed in Table 2. It is also found that the parameter $\gamma_{j}=0$, which means no explanatory variables violated the parallel regression assumption.

The occurrence time is one of the influential factors on crash severity of traffic accident. It is found that accidents occurring during 7-12 a.m. and 13-18 p.m. are less severe than those of 0-6 a.m., while the severity of $18-24$ p.m. is greater. It may be caused by the driver's working condition. The drivers usually have much more energy to operate the vehicle flexibly and the ability to respond appropriately when faced with an emergency during 7-12 a.m. and 13-18 p.m. after giving the body a sleeping rest, while during 0-6 a.m. and 18-24 p.m., the illumination on the mountainous freeway is poor, and the needed visual information is hard to be achieved. It is the right time for the body to rest. The driver is prone to feeling fatigued at such period, which is harmful to traffic safety. So the occurrence probability of serious traffic accident increases. Also it must be noted that the probability of serious traffic accident during 19-24 p.m. is more than that of $0-$ 6 a.m. This shows that the driving conditions during 1924 p.m., such as the driver's visual response, psychological load, the road environment, and the degree of their mutual adaptation, are more unfavorable to the driver.

The occurrence probability of serious traffic accidents in summer and autumn is up while it is down in winter compared with the spring. This may result from the seasonal characteristics of Chongqing mountainous area. The spring weather of Chongqing lasts usually only about forty days. The air temperature and humidity make the driver feel comfortable during travelling. The greening landscape on both sides of mountainous freeway begins to regrow in spring so fresh green and colorful flowers can provide a kind of feeling delightfully fresh to the driver. Chongqing is located in hot summer zone and has a long summer and strong solar radiation. The road pavement can attain temperature of up to $50^{\circ} \mathrm{C}$. The high-temperature environment wears the driver out, which is against the interests of traffic safety. Autumn is the shortest season of the year. It is prone to fog in the mountainous area and even sudden descent of fog, which leads to the reduction of visual driving distance and variations in speed. This may probably be the main cause for maximum probability of serious accidents in autumn. Winter closes in and the temperature drops below freezing in mountain, but there is no icing on the pavement. The cold air could assist the driver with clear state. So the probability of serious traffic accidents in winter decreases. 
TABLE 2: Results of partial proportional odds model.

\begin{tabular}{|c|c|c|c|}
\hline Parameter & Explanatory variable & Coefficients & $z$ \\
\hline & Time & & \\
\hline & $2=06: 00 \sim 12: 00$ & -0.0772 & 2.49 \\
\hline & $3=12: 00 \sim 18: 00$ & -0.1989 & 2.78 \\
\hline & $4=18: 00 \sim 24: 00$ & 0.0551 & 2.43 \\
\hline & Reference: $1=00: 00 \sim 06: 00$ & & \\
\hline & Season & & \\
\hline & $2=$ summer (May - Oct. $)$ & 0.5443 & 3.56 \\
\hline & $3=$ autumn (Nov.) & 0.6246 & 3.28 \\
\hline & $4=$ winter (Dec. - Feb. $)$ & -0.0411 & 2.39 \\
\hline & Reference: 1 = spring (March-April) & & \\
\hline & Involvement of trucks & 0.4982 & 3.88 \\
\hline & Accident form & & \\
\hline & $2=$ sideswipe & -0.6413 & 3.59 \\
\hline & $3=$ turnover & 0.6754 & 3.7 \\
\hline & $4=$ rear-end & 0.0018 & 2.31 \\
\hline & Reference: 1 = with fixed object & & \\
\hline & Violation of speed limit & 2.4455 & 9.46 \\
\hline & Maximum driving experience of at-fault driver & & \\
\hline \multirow{20}{*}{ Beta } & $1-3$ years & -0.2072 & 2.68 \\
\hline & $>3$ years & -0.5387 & 3.48 \\
\hline & Reference: $\leq 1$ year & & \\
\hline & Weather & & \\
\hline & Sunny & -0.2808 & 2.83 \\
\hline & Rainy & -1.2157 & 4.23 \\
\hline & Snow & -2.2874 & 4.1 \\
\hline & Foggy & 1.7105 & 3.89 \\
\hline & Reference: cloudy & & \\
\hline & Section form & & \\
\hline & Toll station & -13.8105 & 2.33 \\
\hline & Service area & -0.5278 & 2.97 \\
\hline & Upgrade & -1.7255 & 3.47 \\
\hline & Downgrade & 1.9346 & 5.48 \\
\hline & Ramp & 2.1329 & 3.98 \\
\hline & Curve & 1.0979 & 4.69 \\
\hline & Construction area & -0.0832 & 2.44 \\
\hline & Bridge & 0.7885 & 4.02 \\
\hline & Tunnel & 0.1135 & 2.57 \\
\hline & Reference: straight & & \\
\hline \multirow{2}{*}{ Alpha } & Constant 1 & -2.6414 & -3.10 \\
\hline & Constant 2 & -3.9607 & -4.55 \\
\hline \multirow{3}{*}{ Summary statistics } & Log likelihood & -232.1337 & \\
\hline & Pseudo $R^{2}$ & 0.1954 & \\
\hline & Number of observations & 898 & \\
\hline
\end{tabular}

The involvement of trucks in an accident is of importance for its severity. The positive beta coefficient of the explanatory variable of the presence of trucks in an accident indicates that the severity may increase if there are trucks involved in the accident. The driver of large trucks can protect himself well due to his good view and structure of trucks. This self-protection may endanger other vehicles. This conclusion is consistent with the previous results [17]. It was found that motorcyclists were particularly vulnerable to injury in crashes with truck due to substantial differences in vehicle mass, protection degree, and speed. For the mountainous freeways in Chongqing, measures such as road sign and camera monitoring were taken to ensure that the truck run on the right lane except overtaking. These measures are aiming 
to separate the truck and other vehicles and reduce mutual interference.

The accident form represents the types of the crashing associated with vehicles. It can be classified into four groups: crash with fixed object, sideswipe, turnover, and rear-end. Taking the first as the reference case, the results showed that the probability of serious accident is small in a sideswipe, generally no more than a cosmetic annoyance. According to the accident investigation, sideswipe occurred mainly at the service area and construction area, where it usually has small speed value, so it is not prone to serious accidents. The probability of serious crash is higher when the accident forms are turnover and rear-end, where the former has highest probability. It may be related with fast release of energy when turnover occurs. Chongqing mountain area has its complicated land shape. The existence of cliff, bridge, and tunnel section aggravates consequences of traffic accidents. The relation between the accident form and crash severity can be found in other references [18].

The driving speed has significant effect on the accident severity. The speed is measured at the sections where it has greater forecast value and is easily found. A driver may speed regardless of the speed limit sign or gun on the mountainous freeway. Two cases (within speed limit and beyond speed limit) were considered. The beta coefficient of this explanatory variable reached 2.4455 , indicating that overspeeding may increase the severity of accidents. Many mountainous freeways in Chongqing have small radius, large longitudinal slopes, and complicated terrain. It is difficult for speeding drivers to timely and accurately judge the external environment. This may increase the crashing energy and thus increase the accident severity. This finding is consistent with the results of some researchers [19].

The maximum driving experience of at-fault drivers can be classified into three groups: $\leq 1$ year, $1-3$ years, and $>3$ years. The beta coefficients for the latter two cases ( $1-3$ years and $>3$ years) are -0.2072 and -0.5387 , respectively. This means that the probability of serious accidents reduces with increasing driving experience. The longer the driving experience is, the more probability the driver can accurately deal with the accident and the lower the accident severity [20]. It is worth noting that the traffic law of Chongqing specifies that when a driver with less than 1 year driving experience drives on the freeway, there must be a passenger with more than one year driving experience sitting in the auxiliary driving position to monitor the driver. However, in case of emergency, it is difficult for the passenger in the auxiliary driving position to correct the driver's behavior timely.

The weather has obvious relation with the accident severity. The bad weather condition has important induced effect on the severity [21]. Taking the cloudy weather as the reference case, the accident severity reduces for sunny, rainy, and snow days. However, there is high probability of serious accidents in foggy days. Careful driving is adopted when it rains. The mountainous freeway will be closed when it is heavy rain or moderate snow, whereby no vehicle is allowed to enter the highway. This may be a reason for lower probability of crash severity in rainy and snow days. Mountainous fog is common in Chongqing. Driving in the fog especially mist, the visual view of the driver is reduced which is not suitable for driving safety and is prone to cause severity accidents.

The crash severity of mountainous freeway depends on its alignment. To study the effect of road alignment on the accident severity, the alignment factor is classified into ten groups: straight section, toll station, service area, upgrade, downgrade, ramp, curve, construction area, bridge, and tunnel. Taking the straight section as the reference case, there is low accident severity for toll station, service area, upgrade, and construction area. For other sections, there is higher probability of serious accidents. This may be caused by different speed in various sections. At toll station, service area, upgrade sections, and construction areas, the speed is usually low or restricted, even if there is traffic accident, the consequences are often not serious, while the larger beta value of downgrade and ramp represents the fact that it is prone to serious traffic accidents. The speed of downgrade is often higher, and the speed is difficult to coordinate in the section of ramp connecting with the main road. The relatively high speed and inconsistent speed contribute to the increasing of crash severity.

\section{Conclusion}

The objective of this paper is to study the effect of various factors on the crash severity of mountainous freeway in Chongqing. It aims to provide reasonable reference for the traffic safety of mountainous freeways subjected to high temperature and rainy, varied terrain, complicated alignment, and more structures.

The crash severity is classified into three levels: minor, moderate, and serious accidents. The partial proportional odds model was used considering the discrete ordered dependent variables. This model can check and deal with the explanatory variables violating the parallel regression assumption and thus credible results are obtained.

According to the records of 898 accidents occurring on mountainous freeway in Chongqing during the past 6 years, eight influencing factors on the crash severity were selected considering the human behavior, vehicle, and road and weather factors. The eight explanatory variables include time, season, trucks involved, accident form, speeding, maximum driving experience of at-fault driver, weather, and section form. The influence of these factors on the crash severity was studied.

The results showed that none of explanatory variables in calculation violated the parallel regression assumption.

At the time of 0-6 a.m. and 19-24 p.m., it is prone to serious traffic accidents, which may be related to the driver's physiological and psychological state in this period. The probability of serious traffic accidents is greater in summer and autumn. The involvement of trucks is of significant importance for the crash severity. Managements such as speed limit and camera monitor should be taken. Turnover and rear-end frequently cause serious accidents. The speeding driving always causes serious accidents. The possibility of using a lower speed limit should be studied. Drivers with rich driving experience are not prone to cause serious accidents. It is 
recommended for drivers with less than 1 year driving experience to follow the advice from drivers with rich experience. There is high probability of serious accidents in bad weather conditions, especially foggy days. Measures should be taken to control the visual induction in foggy weather. Serious traffic accidents are prone to occur on the downgrade, ramp, curve, bridge, and tunnel.

The occurrence time and season of traffic accidents have a direct impact on crash severity. It can be explained by the visual psychological load of the driver. There are usually no road illumination along the mountainous freeway except toll station. The driver just has to rely on the car lights in travelling. It can be imagined that poor visual environment is posed on the drivers in night and foggy days. In such an environment, drivers have to constantly adjust the physiological and psychological state to accommodate the changing environment of mountain highway. So the serious crash accidents are easily caused by the disharmony and nervous driving load in the night and foggy autumn. In addition, it also has a greater occurrence probability of serious traffic accidents in the hot summer. For maintenance of freeway, reasonable lighting facilities, signs, and lane markings should be set at the sections of higher accident rate.

For the traffic management, there should be tougher restrictions such as truck driving on the right lane and separating from other vehicles. More signs of speed limit and keep space and more speed detection devices should be set in order to reduce the vehicle's speed. During the training period of license test, the exercise of drivers driving on the mountain highway should be paid more attention and the emergency handling capacity should be added. It should also promote cooperation between the transportation department and meteorological forecast department. The drivers could obtain timely weather information road ahead.

Traffic accident is a small probability event, which is influenced by human, vehicle, road, and environmental factors. In the research on crash severity in Chongqing's mountainous freeway, some findings having the mountain highway characteristics could be gained.

(1) Seasonal factors have an important influence on the crash severity. One of the characteristics of the climate in Chongqing is being very hot in summer and cold in winter, with shorter period of spring and autumn. In the extremely high temperature of summer, the probability of serious traffic accidents is greater. When the road is built in the valley, it is prone to fog in autumn and winter, so higher probability of serious crash is expected.

(2) Speeding easily causes serious traffic accident, so strict speed limit measures should be set.

(3) The alignment of mountainous freeway is related to the crash severity, and sections having low alignment index or more structures are prone to serious crash.

This paper investigated the effect of various explanatory variables on the crash severity and provided recommendations for safe driving. The results compared with other existing reports and almost conclusions was obtained. It just shows that the rules of traffic crash severity in Chongqing mountainous freeway are in tune with different types of highways. The author believes it is also a contribution to traffic crash prediction and prevention. The study was based on the realistic accident data which is recorded by the traffic officers where some information may be missed. In addition, the effect of fatigue driving was not considered in this study which needed further work.

\section{Competing Interests}

The author declares that he has no competing interests.

\section{Acknowledgments}

This work was funded by Chongqing Science \& Technology Commission (no. cstc2015shmszx30007). The author is grateful to the authors of cited papers.

\section{References}

[1] S. Kaplan and C. G. Prato, "Risk factors associated with bus accident severity in the United States: a generalized ordered logit model," Journal of Safety Research, vol. 43, no. 3, pp. 171-180, 2012.

[2] C. Zhang, X. Guo, Y. Wang, Y. Li, and N. Zhang, "What leads to severe mountainous freeway crashes in southeast of China?" Technical Gazette, vol. 23, no. 6, pp. 1747-1753, 2016.

[3] C. Lee and X. Li, "Analysis of injury severity of drivers involved in single- and two-vehicle crashes on highways in Ontario," Accident Analysis and Prevention, vol. 71, pp. 286-295, 2014.

[4] X. Zhu and S. Srinivasan, "A comprehensive analysis of factors influencing the injury severity of large-truck crashes," Accident Analysis and Prevention, vol. 43, no. 1, pp. 49-57, 2011.

[5] C. Roque, F. Moura, and J. Lourenço Cardoso, "Detecting unforgiving roadside contributors through the severity analysis of ran-off-road crashes," Accident Analysis and Prevention, vol. 80, pp. 262-273, 2015.

[6] E. Ayati, M. A. P. Neghab, A. Sadeghi, and A. M. Moghaddam, "Introducing roadside hazard severity indicator based on evidential reasoning approach," Safety Science, vol. 50, no. 7, pp. 1618-1626, 2012.

[7] D. Jaroszweski and T. McNamara, "The influence of rainfall on road accidents in urban areas: a weather radar approach," Travel Behaviour and Society, vol. 1, no. 1, pp. 15-21, 2014.

[8] K. A. Abay, R. Paleti, and C. R. Bhat, "The joint analysis of injury severity of drivers in two-vehicle crashes accommodating seat belt use endogeneity," Transportation Research Part B: Methodological, vol. 50, pp. 74-89, 2013.

[9] A. Polus, M. A. Pollatschek, and H. Farah, "Impact of infrastructure characteristics on road crashes on two-lane highways," Traffic Injury Prevention, vol. 6, no. 3, pp. 240-247, 2005.

[10] R. Yu and M. Abdel-Aty, "Analyzing crash injury severity for a mountainous freeway incorporating real-time traffic and weather data," Safety Science, vol. 63, pp. 50-56, 2014.

[11] P. Michalaki, M. A. Quddus, D. Pitfield, and A. Huetson, "Exploring the factors affecting motorway accident severity in England using the generalised ordered logistic regression model," Journal of Safety Research, vol. 55, pp. 89-97, 2015. 
[12] J. D. Lemp, K. M. Kockelman, and A. Unnikrishnan, "Analysis of large truck crash severity using heteroskedastic ordered probit models," Accident Analysis and Prevention, vol. 43, no. 1, pp. 370-380, 2011.

[13] G. Khan, A. R. Bill, and D. A. Noyce, "Exploring the feasibility of classification trees versus ordinal discrete choice models for analyzing crash severity," Transportation Research Part C: Emerging Technologies, vol. 50, pp. 86-96, 2015.

[14] D. Eustace, V. K. Indupuru, and P. Hovey, "Identification of risk factors associated with motorcycle-related fatalities in ohio," Journal of Transportation Engineering, vol. 137, no. 7, pp. 474480, 2011.

[15] B. Peterson and F. E. Harrell, "Partial proportional odds models for ordinal response variables," Applied Statistics, vol. 39, no. 2, pp. 205-217, 1990.

[16] J. Mooradian, J. N. Ivan, N. Ravishanker, and S. Hu, "Analysis of driver and passenger crash injury severity using partial proportional odds models," Accident Analysis and Prevention, vol. 58, pp. 53-58, 2013.

[17] T. H. Law, M. Ghanbari, H. Hamid, A. Abdul-Halin, and C. P. Ng, "Examining the effect of visual treatments on truck drivers' time-to-arrival judgments of motorcycles at T-intersections," Transportation Research Part F: Traffic Psychology and Behaviour, vol. 33, pp. 66-74, 2015.

[18] S. Park, K. Jang, S. H. Park, D.-K. Kim, and K. S. Chon, "Analysis of injury severity in traffic crashes: a case study of Korean expressways," KSCE Journal of Civil Engineering, vol. 16, no. 7, pp. 1280-1288, 2012.

[19] C. D. Fitzpatrick, I. A. McKinnon, F. T. Tainter, and M. A. Knodler, "The application of continuous speed data for setting rational speed limits and improving roadway safety," Safety Science, vol. 85, pp. 171-178, 2016.

[20] T. Seacrist, A. Belwadi, A. Prabahar, S. Chamberlain, J. Megariotis, and H. Loeb, "Comparison of crash rates and rear-end striking crashes among novice teens and experienced adults using the SHRP2 Naturalistic Driving Study," Traffic Injury Prevention, vol. 17, supplement 1, pp. 48-52, 2016.

[21] R. Yu, Y. Xiong, and M. Abdel-Aty, "A correlated random parameter approach to investigate the effects of weather conditions on crash risk for a mountainous freeway," Transportation Research Part C: Emerging Technologies, vol. 50, pp. 68-77, 2015. 


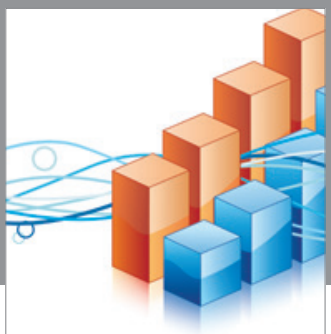

Advances in

Operations Research

vatem alat4

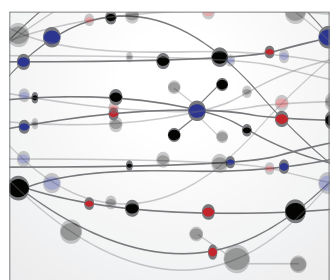

\section{The Scientific} World Journal
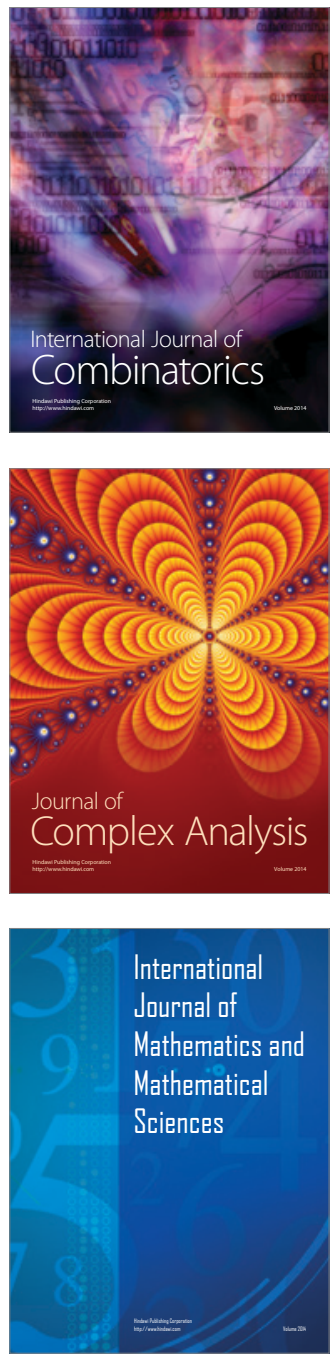
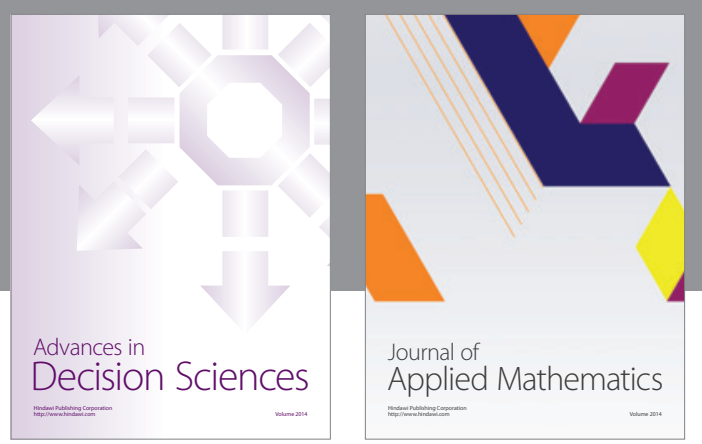

Algebra

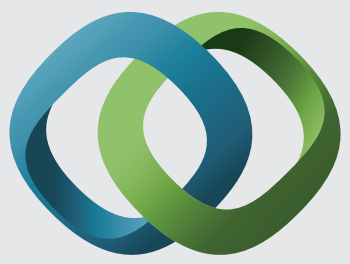

\section{Hindawi}

Submit your manuscripts at

https://www.hindawi.com
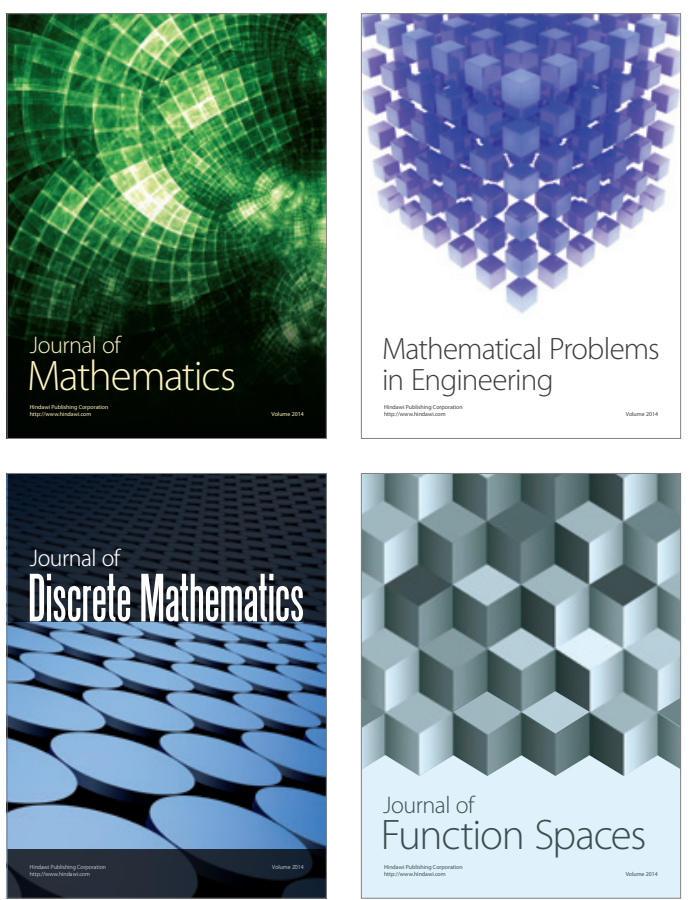

Mathematical Problems in Engineering
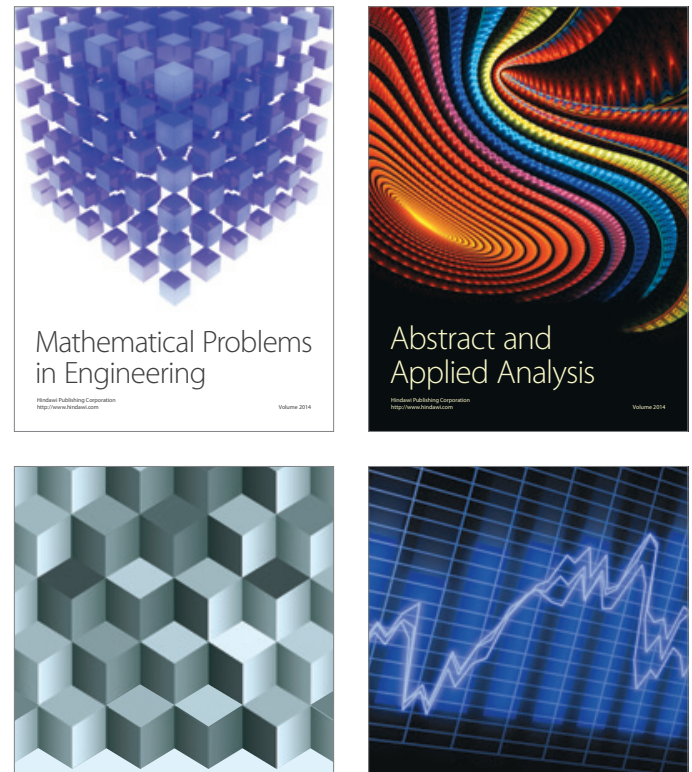

Journal of

Function Spaces

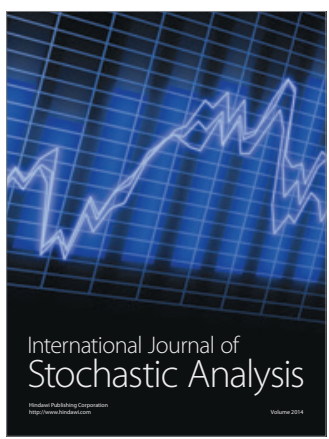

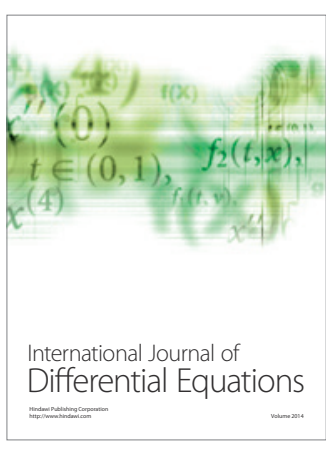
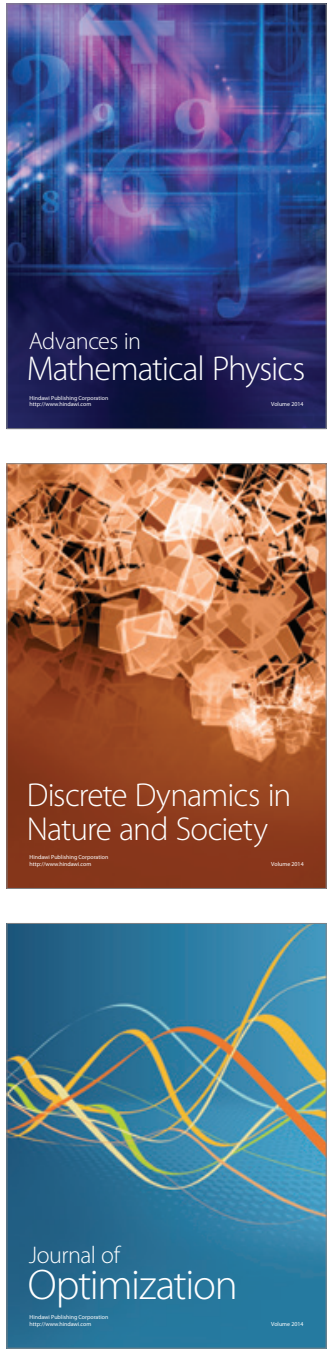